\title{
Bilateral Corpus Cavernosum and Complete Urethral Rupture: A Double Trouble
}

\author{
Doğukan Sökmen $^{1}$, Yusuf İ. Çömez ${ }^{2,1}$ \\ 1. Urology, Memorial Bahçelievler Hospital, Istanbul, TUR 2. Urology, Üsküdar University, Istanbul, TUR
}

Corresponding author: Doğukan Sökmen, drdogukansokmen@gmail.com

\begin{abstract}
Penile fracture is a rare urologic emergency. The main finding is a partial disruption of one or both cavernosal bodies due to blunt trauma of the penis during an erection. Complete or partial injury of the urethra may accompany the penile fracture but complete urethral rupture is rarely encountered. In this study, we present the management of a penile fracture case with disruption of both corpus cavernosum with total urethral rupture.
\end{abstract}

Categories: Urology, Trauma

Keywords: penile fracture, urethral rupture, corpus cavernosum

\section{Introduction}

Penile fracture (PF) is defined as the rupture of the tunica albuginea and corpora cavernosa, often caused by blunt trauma to the penis during sexual intercourse [1]. The coexistence of PF and urethral injury is not a common condition, and it has been reported in the range of 8-23\% [2]. Besides PF symptoms like penile pain, a popping or cracking sound and rapid loss of erection, blood in the urethral meatus, hematuria, and urinary retention should be assessed as a sign of urethral injury [3]. Urgent surgical repair is recommended to prevent complications such as erectile dysfunction, penile curvature, and urethral stricture [4].

This study aimed to present a case with bilateral corpus cavernosum and complete urethral rupture after blunt trauma to the penis during sexual intercourse and describe the surgical technique applied.

\section{Case Presentation}

A 21-year-old male patient presented to our emergency clinic two hours after blunt injury of the penis during sexual intercourse. He expressed that he had been forced towards the perineum of his partner at the beginning of the intercourse. He heard a cracking sound and afterward had severe pain, detumescence, and little blood at the urethral meatus. He had not yet tried to void. Tumefaction and hematoma over the entire penile shaft were seen during physical examination. There was a palpable defect at the ventral shaft of the penis. The scrotal examination was normal. The bladder was not distended. Ultrasonography (USG) showed

Review began 04/12/2021 Review ended 04/29/2021 Published 06/06/2021

(c) Copyright 2021

Sökmen et al. This is an open access article distributed under the terms of the Creative Commons Attribution License CC-BY 4.0., which permits unrestricted use, distribution, and reproduction in any medium, provided the original author and source are credited. hematoma and irregularity of corpora cavernosum at the mid-ventral side of the penis. The patient was informed about the potential postoperative complications and the risks of choosing a conservative approach. He underwent emergency surgery after his approval.

After fluid infusion and antibiotic prophylaxis, under spinal anesthesia, a penile subcoronal circumferential incision was performed and the hematoma was evacuated. Both cavernosal ruptures on the mid-ventral side of the penis were clearly seen but the urethra could not be identified at the level of the defect (Figure 1a). An 18-French urethral catheter was inserted from the meatus towards the disrupted urethra (Figure $1 b$ ). The integrity of the proximal part of the urethra was checked via insertion of the catheter into the bladder (Figure 1 c). Corpus cavernosal defects were repaired separately by absorbable polydioxanone stitches (Figure $1 d$ ). 


\section{Cureus}
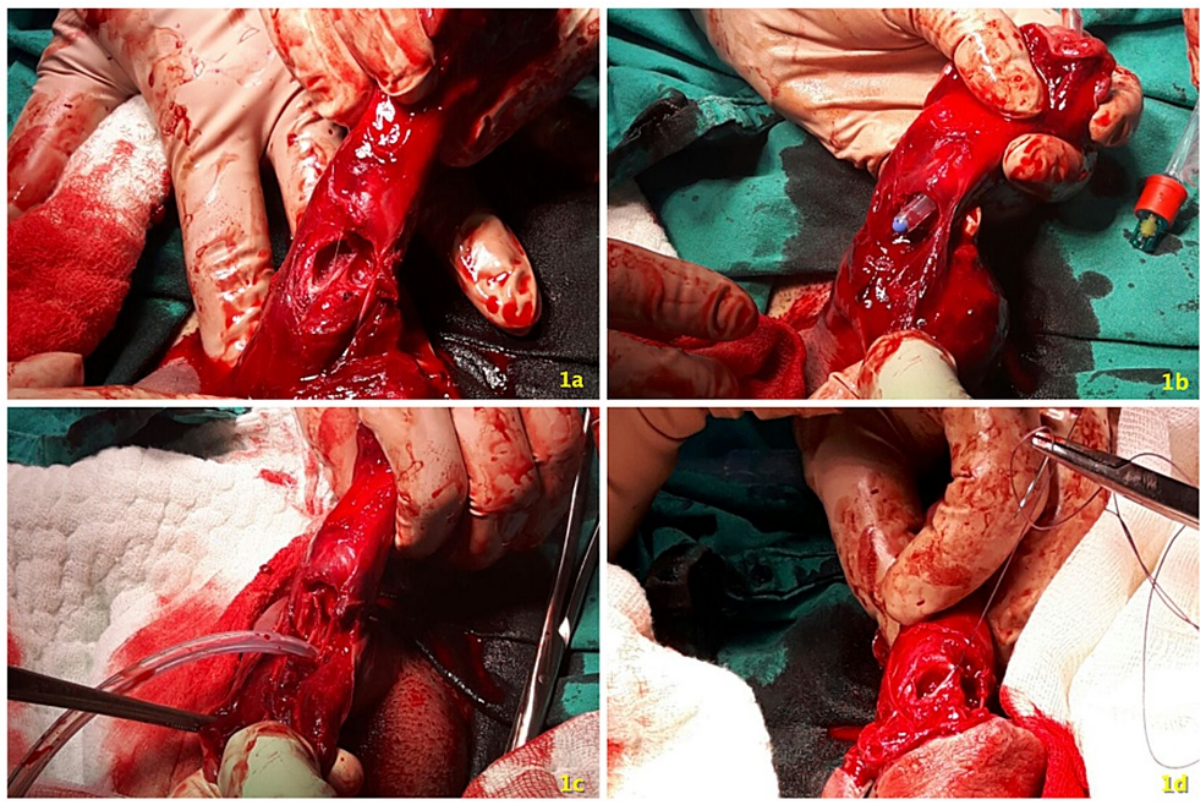

FIGURE 1: Bilateral cavernosal rupture (a). Identifying urethra with an 18-French catheter (b). Checking proximal urethra (c). Suturing cavernosal defects separately (d).

The end-to-end urethral anastomosis was performed with 4/0 Vicryl separate stitches with the guidance of the urethral catheter (Figures $2 a, 2 b$ ).
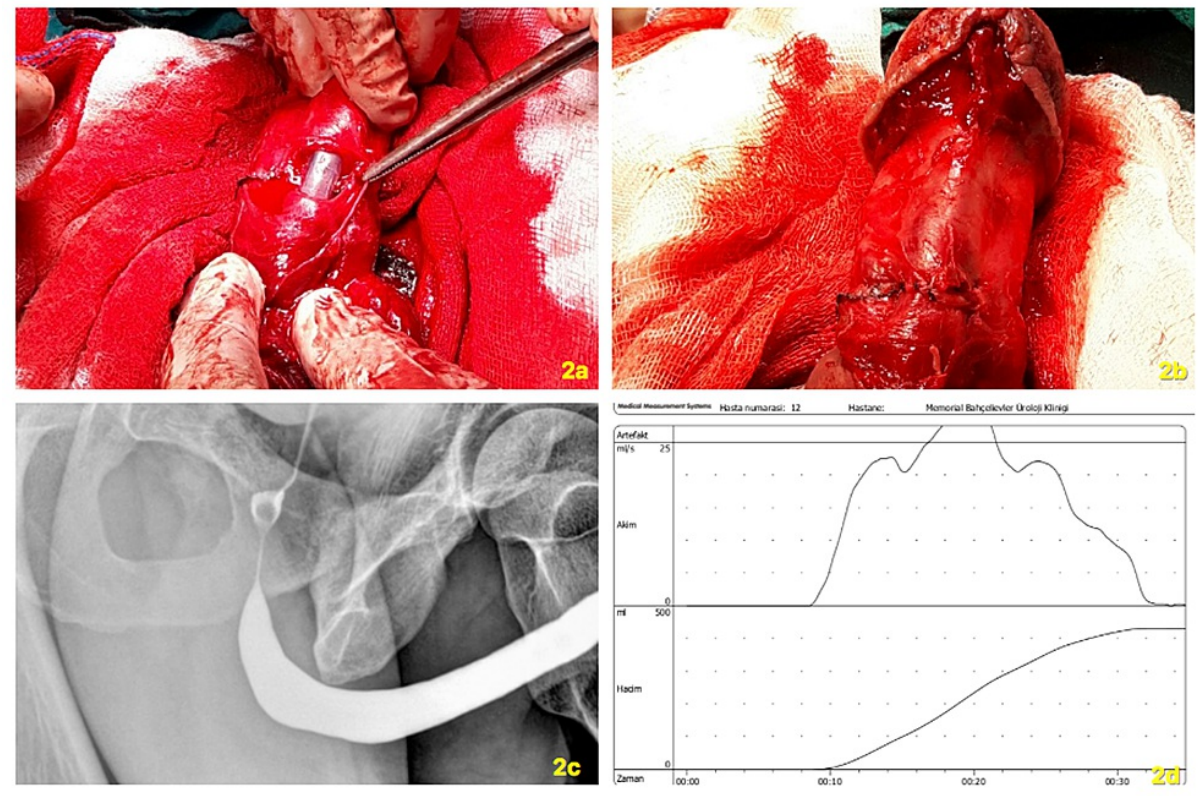

FIGURE 2: Urethral reconstruction (a). Both cavernosal and urethral defects are repaired (b). Retrograde urethrography at postoperative third month (c). Uroflowmetry at postoperative third month (d).

The patient was discharged two days after surgery. The urethral catheter was removed on the 14th postoperative day and he could void normally. Diazepam has been prescribed for painful erection at the early postoperative period. He had normal erectile and voiding functions one month later. A point defect was palpable on the ventral side of the penis shaft at physical examination and he expressed a slight $\left(5-10^{\circ}\right)$ penile curvature on the left side during erection without difficulties during sexual intercourse. At a threemonth follow-up, the patient was evaluated with retrograde urethrography (RGU) that documented a regular 
urethral profile without signs of stricture neither fistula (Figure $2 c$ ). Uroflowmetry demonstrating an average flow rate of $16.6 \mathrm{ml} / \mathrm{s}$ and a maximum flow rate of $30.6 \mathrm{ml} / \mathrm{s}$ (Figure $2 d$ ). Validated questionnaires demonstrated optimal functional outcomes. (International Prostate Symptoms Score (IPSS) $=3$ and International Index of Erectile Function-5 (IIEF-5) = 23) (Figure 2d).

\section{Discussion}

Penile fractures are rare urologic emergencies with an incidence of one in 175,000 cases [5]. Bilateral corpus cavernosal rupture is a rare event and is observed in only $10 \%$ of the PF cases. The history and clinical examination are usually adequate for the diagnosis [6]. In case of suspicion in clinical diagnosis, USG, cavernosography, and MRI may be helpful [7]. Surgery and a conservative approach are the treatment modalities for penile fracture. Immediate surgical repair is the most chosen treatment modality and provides better outcomes and fewer complications than conservative management [8]. Postoperative complications, such as erectile dysfunction, penile plaques and nodules, chordee, and penile pain, are the main complications [4]. Conservative treatment may lead to an increased risk of complications [7]. In our case, early surgical intervention was chosen according to USG, clinical signs, and physical examination.

Associated urethral injury rates vary from $8 \%$ to $23 \%$ [2]. A concomitant urethral injury should always be suspected if the presence of blood at meatus, microscopic or gross hematuria, and disorders of voiding are encountered [4]. However, these symptoms are not always present in all patients with urethral injury. In a systematic review published recently, it was stated that $50 \%$ of urethral injuries are asymptomatic and detected incidentally by USG or intraoperatively [3]. However, RGU has a false negativity rate of $28.5 \%$ [9]. Additionally, Kamdar et al. recommended the simultaneous use of flexible cystoscope for PF cases with suspected urethral injury [10]. Although the sensitivity of the MRI examination for penile fracture is reported as $100 \%$ and the specificity is $77.8 \%$, its sensitivity for concomitant urethral trauma has been reported as $60 \%$ and specificity as $78.3 \%$ [11]. In our case, we did not perform MRI as suspicion of penile fracture was high from clinical examination/ultrasound.

Urethral injuries should be treated according to the size of the injury. For partial injuries, urinary diversion or primary suturation of the rupture can be adequate [4]. However, for complete urethral transections, complex procedures such as tension-free anastomotic or augmentation urethroplasty are needed [2].

Postoperative urethral catheterization time should be determined according to the complexity of the injury. Catheterization is required for 10-14 days in the presence of partial injury and 14-21 days in the presence of complete rupture [12]. The baseline diagnostic methods recommended to evaluate postoperative voiding functions are the IPSS questionnaire and uroflowmetry [3]. In some studies, $30 \%$ of the cases with PF who underwent urethral reconstruction have been found to be impaired in IPSS [12,13]. Urethral stricture, pseudoaneurysm, urethrocutaneous fistulas, and related subcutaneous abscesses may develop in the postoperative long term [4]. In our case, the patient did not have any early or late complications. He had a regular sexual relationship with no anxiety.

\section{Conclusions}

Penile fracture is a rare urological emergency. The main problems are late diagnosis and surgical intervention. Although partial urethral rupture may accompany the penile fracture occasionally complete urethral rupture is very rare. In case of penile fracture, the concomitant urethral rupture has to be suspected. Immediate surgical repair will ensure satisfactory results and lesser complications.

\section{Additional Information}

\section{Disclosures}

Human subjects: Consent was obtained or waived by all participants in this study. Conflicts of interest: In compliance with the ICMJE uniform disclosure form, all authors declare the following: Payment/services info: All authors have declared that no financial support was received from any organization for the submitted work. Financial relationships: All authors have declared that they have no financial relationships at present or within the previous three years with any organizations that might have an interest in the submitted work. Other relationships: All authors have declared that there are no other relationships or activities that could appear to have influenced the submitted work.

\section{References}

1. Amer T, Wilson R, Chlosta P, AlBuheissi S, Qazi H, Fraser M, Aboumarzouk OM: Penile fracture: a metaanalysis. Urol Int. 2016, 96:315-329. 10.1159/000444884

2. Ibrahiem el-HI, el-Tholoth HS, Mohsen T, Hekal IA, el-Assmy A: Penile fracture: long-term outcome of immediate surgical intervention. Urology. 2010, 75:108-111. 10.1016/j.urology.2009.08.057

3. Falcone M, Garaffa G, Castiglione F, Ralph DJ: Current management of penile fracture: an up-to-date systematic review. Sex Med Rev. 2018, 6:253-260. 10.1016/j.sxmr.2017.07.009

4. Hanna KF, Jiang J, Burns N, Engelsgjerd JS, Davies JD: A case of traumatic penile fracture with simultaneous rupture of both corpora cavernosa and complete urethral transection. Urol Case Rep. 2021, 34:101439. 


\section{Cureus}

10.1016/j.eucr.2020.101439

5. Koifman L, Barros R, Júnior RA, Cavalcanti AG, Favorito LA: Penile fracture: diagnosis, treatment and outcomes of 150 patients. Urology. 2010, 76:1488-1492. 10.1016/j.urology.2010.05.043

6. El Malik el FM, Ghali AM, Ibrahim AI, Rashid M: Fracture of the penis: a critique of clinical features and management. Ann Saudi Med. 1997, 17:558-561. 10.5144/0256-4947.1997.558

7. Eke N: Fournier's gangrene: a review of 1726 cases . Br J Surg. 2000, 87:718-728. 10.1046/j.13652168.2000.01497.x

8. Wong N, Dason S, Bansal R, Davies T, Braga L: Pd3-11 can it wait? - a systematic review of immediate versus delayed surgical repair of penile fracture. J Urol. 2014, 191:23-24. 10.1016/j.juro.2014.02.156

9. Mydlo JH, Hayyeri M, Macchia RJ: Urethrography and cavernosography imaging in a small series of penile fractures: a comparison with surgical findings. Urology. 1998, 51:616-619. 10.1016/S0090-4295(97)00701-2

10. Kamdar C, Mooppan UMM, Kim H, Gulmi FA: Penile fracture: preoperative evaluation and surgical technique for optimal patient outcome. BJU Int. 2008, 102:1640-1644. 10.1111/j.1464-410X.2008.07902.x

11. Sokolakis I, Schubert T, Oelschlaeger M, et al.: The role of magnetic resonance imaging in the diagnosis of penile fracture in real-life emergency settings: comparative analysis with intraoperative findings. J Urol. 2019, 202:552-557. 10.1097/JU.0000000000000211

12. Barros R, Silva MIS, Antonucci V, Schulze L, Koifman L, Favorito LA: Primary urethral reconstruction results in penile fracture. Ann R Coll Surg Engl. 2018, 100:21-25. 10.1308/rcsann.2017.0098

13. Hatzichristodoulou G, Dorstewitz A, Gschwend JE, Herkommer K, Zantl N: Surgical management of penile fracture and long-term outcome on erectile function and voiding. J Sex Med. 2013, 10:1424-1430. 10.1111/jsm.12107 